\title{
CORRECTION
}

View Article Online

View Journal I View Issue

Check for updates

Cite this: RSC Adv., 2020, 10, 13991

\section{Correction: Self-assembled fibrillar networks comprised of a naturally-occurring cyclic peptide- LOB3}

\author{
M. A. Rogers, ${ }^{* a}$ Q. Feng, ${ }^{\text {a }}$ V. Ladizhansky, ${ }^{\text {b D. B. Good, }}{ }^{\text {b }}$ A. K. Smith, ${ }^{a}$ M. Corridini, ${ }^{c}$ \\ D. A. S. Grahame, ${ }^{a}$ B. C. Bryksa, ${ }^{a}$ P. D. Jadhav, ${ }^{d}$ S. Sammynaiken, ${ }^{e}$ L.-T. Lim, ${ }^{a}$ B. Guild, ${ }^{a}$ \\ Y. Y. Shim, ${ }^{d}$ P.-G. Burnett ${ }^{d}$ and M. J. T. Reaney ${ }^{d f}$
}

DOI: 10.1039/d0ra90035d

rsc.li/rsc-advances

Correction for 'Self-assembled fibrillar networks comprised of a naturally-occurring cyclic peptide-LOB3' by M. A. Rogers et al., RSC Adv., 2016, 6, 40765-40776.

The authors regret the omission of the following conflict of interest statement.

Dr Martin J. T. Reaney is the founder of, and has an equity interest in, Prairie Tide Diversified Inc. (PTD, Saskatoon, SK, Canada: previous company name is Prairie Tide Chemicals Inc.). Dr Youn Young Shim is a Market Consultant for PTD in Korea. The terms of this arrangement have been reviewed and approved by the University of Saskatchewan in accordance with its conflict of interest policies.

The Royal Society of Chemistry apologises for these errors and any consequent inconvenience to authors and readers.

\footnotetext{
aDepartment of Food Science, University of Guelph, Guelph, ON, N1G 2W1, Canada. E-mail: mroger09@uoguelph.ca; Tel: +1 5198244120 ext. 54327

${ }^{b}$ Department of Physics, University of Guelph, Guelph, ON, N1G 2W1, Canada

'Department of Food Science, Rutgers University, New Brunswick, NJ, 08901-8520, USA

${ }^{d}$ Department of Plant Sciences, University of Saskatchewan, Saskatoon, SK, S7N 5A8, Canada

${ }^{e}$ Saskatchewan Structural Sciences Centre, University of Saskatchewan, Saskatoon, SK, S7N 5C9, Canada

${ }^{f}$ Guangdong Saskatchewan Oilseed Joint Laboratory, Department of Food Science and Engineering, Jinan University, Guangzhou, Guangdong, 510632, People's Republic of China
} 